\title{
Article \\ The Digital Revolution in the Urban Water Cycle and Its Ethical-Political Implications: A Critical Perspective
}

\author{
Lucia Alexandra Popartan ${ }^{1, *}$, Àtia Cortés ${ }^{2}{ }^{(}$, Manel Garrido-Baserba ${ }^{3}$, Marta Verdaguer ${ }^{1}$, Manel Poch ${ }^{1}(\mathbb{D}$ \\ and Karina Gibert ${ }^{4}$ (D)
}

check for

updates

Citation: Popartan, L.A.; Cortés, À.; Garrido-Baserba, M.; Verdaguer, M.; Poch, M.; Gibert, K. The Digital Revolution in the Urban Water Cycle and Its Ethical-Political Implications: A Critical Perspective. Appl. Sci. 2022, 12, 2511. https://doi.org/10.3390/ app12052511

Academic Editor: Jega

Veeriah Jegatheesan

Received: 31 January 2022

Accepted: 23 February 2022

Published: 28 February 2022

Publisher's Note: MDPI stays neutral with regard to jurisdictional claims in published maps and institutional affiliations.

Copyright: (C) 2022 by the authors. Licensee MDPI, Basel, Switzerland. This article is an open access article distributed under the terms and conditions of the Creative Commons Attribution (CC BY) license (https:// creativecommons.org/licenses/by/ $4.0 /)$.
1 LEQUIA, Institute of the Environment, Universitat de Girona, c/ Maria Aurèlia Capmany 69 Catalonia, 17003 Girona, Spain; marta.verdaguer@udg.edu (M.V.); manuel.poch@udg.edu (M.P.)

2 Barcelona Supercomputing Center, Edifici Omega 201, Jordi Girona 1 and 3, 08034 Barcelona, Spain; atia.cortes@bsc.es

3 inCTRL Solutions Corp., Salt Lake City, UT 84123-2583, USA; mgarrido@inctrl.com

4 Intelligent Data Science and Artificial Intelligence Research Center and Institut de Ciència i Tecnologia de la Sostenibilitat, Universitat Politècnica de Catalunya-BarcelonaTech, 08001 Barcelona, Spain;

karina.gibert@upc.edu

* Correspondence: luciaalexandra.popartan@udg.edu

\begin{abstract}
The development and application of new forms of automation and monitoring, data mining, and the use of AI data sources and knowledge management tools in the water sector has been compared to a 'digital revolution'. The state-of-the-art literature has analysed this transformation from predominantly technical and positive perspectives, emphasising the benefits of digitalisation in the water sector. Meanwhile, there is a conspicuous lack of critical literature on this topic. To bridge this gap, the paper advances a critical overview of the state-of-the art scholarship on water digitalisation, looking at the sociopolitical and ethical concerns these technologies generate. We did this by analysing relevant AI applications at each of the three levels of the UWC: technical, operational, and sociopolitical. By drawing on the precepts of urban political ecology, we propose a hydrosocial approach to the so-called 'digital water', which aims to overcome the one-sidedness of the technocratic and/or positive approaches to this issue. Thus, the contribution of this article is a new theoretical framework which can be operationalised in order to analyse the ethical-political implications of the deployment of AI in urban water management. From the overview of opportunities and concerns presented in this paper, it emerges that a hydrosocial approach to digital water management is timely and necessary. The proposed framework envisions AI as a force in the service of the human right to water, the implementation of which needs to be (1) critical, in that it takes into consideration gender, race, class, and other sources of discrimination and orients algorithms according to key principles and values; (2) democratic and participatory, i.e., it combines a concern for efficiency with sensitivity to issues of fairness or justice; and (3) interdisciplinary, meaning that it integrates social sciences and natural sciences from the outset in all applications.
\end{abstract}

Keywords: Artificial Intelligence; urban water cycle; hydrosocial urban cycle; urban political ecology

\section{Introduction}

Digital technologies, particularly those related to Artificial Intelligence, are dramatically transforming our lives and the environment. Urban Water Cycle (UWC) management is a key part of this transformation. The UWC covers all the services related to the extraction, supply and sanitation of waters in a city (see Figure 1). The management of the UWC includes all the water that is present in urban environments: natural surface water, groundwater, drinking water, sewage, stormwater, flood overflow water, and recycled water (stormwater harvesting, managed aquifer recharge, etc.) [1]. In recent years, UWC management has been dramatically transformed by the development and application of 
new forms of automation and monitoring, as well as the use of AI data sources and knowledge management tools. This so-called "digital revolution" [2,3] has received considerable attention in both research and practitioner circles. The studies focused on this transformation can be grouped into three main categories: first, the tech companies developing digital applications in the water sector present an overwhelmingly positive angle, emphasising the benefits of digitalisation (for an overview, see [3]). Second, scholars coming from water, environmental engineering, and data science fields, who mainly focus on developing and refining existing tools [4-6], also frame digitalisation as a fundamentally positive trend. While some legal and ethical issues are marginally mentioned, this type of analysis presents the intertwining of AI with Big Data science and water management as a 'revolution' in the sector, which opens new ways to analyse, organise, and extract information from large volumes of varying types of data [2,7]. Finally, an emerging literature unpacks the more problematic aspects of water digitalisation [8], but the discussion of the broader sociopolitical implications of this process remains overly sketchy.

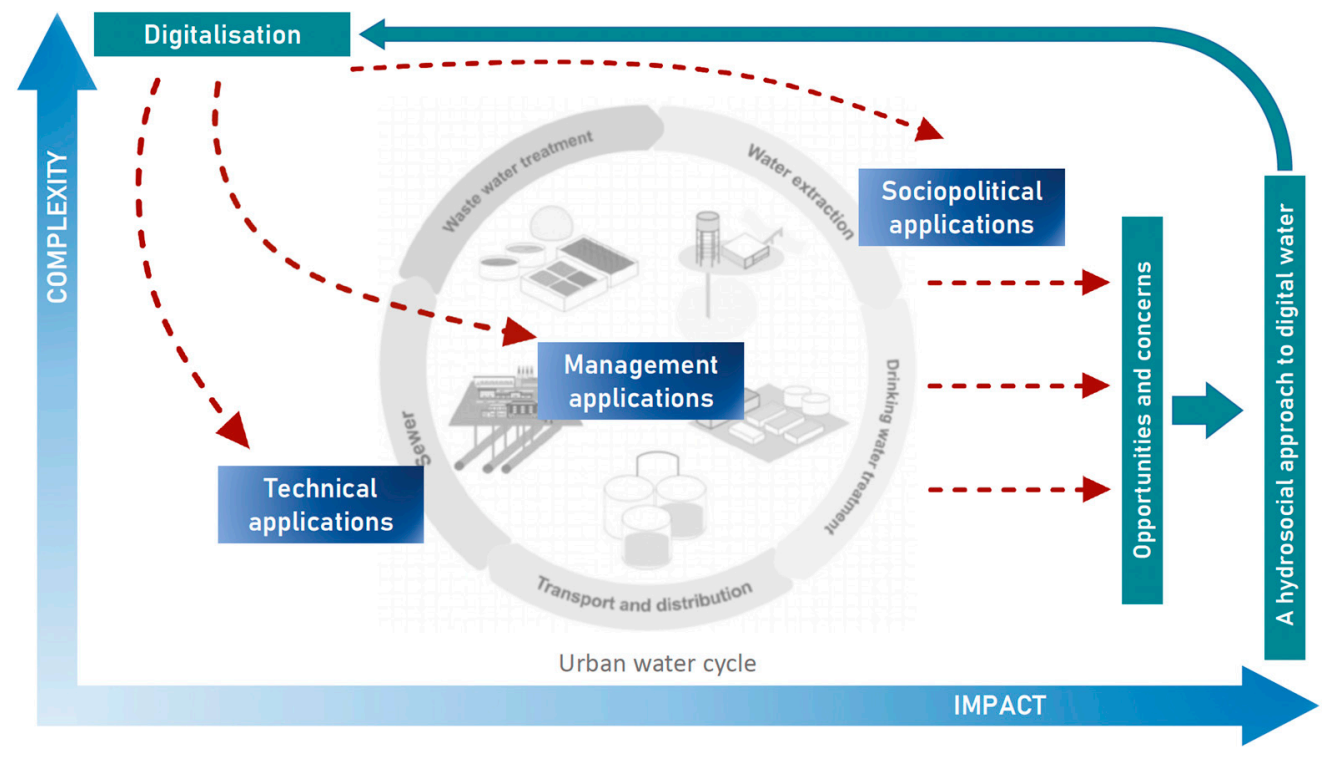

Figure 1. Impact of digitalisation on the UWC.

The lack of critical work on this topic is surprising, given the interest in digitalisation and the proliferation of scientific works devoted to concerns related to AI in general. Scholars of ethics, politics, and technology have unveiled the outright dangers of the unchecked deployment of AI applications, with notorious examples of thinkers such as Shoshana Zuboff [9,10], Noah Yuval Harari [11], and Byung-Chul Han [12] devoting entire volumes to-often dystopian-AI futures. The increase in the references focused on ethics in AI is another indicator; in this sense, see [13-17]. The lack of specific critical attention to the applications of $\mathrm{AI}$ in water management is even more puzzling if we consider the importance and ubiquity of water not only as a source of life, but also as a carrier of data and, as an increasingly scarce resource, an object of political conflict. In the context of the overwhelmingly positive accounts of AI application in water management, this paper aims to offer a more nuanced view of the impact of digitalisation in the sector and to look at 'both sides of the coin', which any transformation of this magnitude necessarily possesses. Drawing on the precepts of urban political ecology (Section 2), we propose a hydrosocial approach to digital water management which aims to integrate and overcome the one-sidedness of the state-of-the art approaches to this issue. Thus, the contribution of the article is a new theoretical framework which can be operationalised to analyse the ethical-political implications of the deployment of AI in urban water management.

The paper performs a critical overview of the state-of-the art scholarship on AI applications in water management, looking at both the opportunities and the concerns they 
generate. However, selecting relevant examples can be problematic, given that the influence of $\mathrm{AI}$ and related technologies in the water sector is extremely wide: data science, augmented intelligence techniques, and automation have enabled innumerable applications, from virtual representation of the water system and near-real time flow and quality monitoring to asset management. Therefore, following our methodology (Section 2), we decided to focus on examples that had more potential to result in ethical or political problems. Moreover, we covered each of the three levels of complexity vs. impact in the water sector proposed by Poch et al. [18] and inspired by Funtowicz and Ravetz [19]: the technical, the operational, and the sociopolitical (Figure 1).

The structure of the paper is organised according to these three levels. Thus, in Section 3, we take two examples of technological developments enabled by digitalisation: smart metering and sewer epidemiology. The former refers to the instant measurement of households' water consumption. The latter is the extraction of biological data from wastewater to identify geographical patterns of disease spread, substance consumption, etc., a technique that has become especially popular during the COVID-19 pandemic. The second level corresponds to the design and operation of urban water cycle infrastructures. In Section 4, we refer to Decision Support Systems (DSS), a technology widely used to help in the choice of treatment plants to be included in the urban water cycle. We also look at how AI enables increased optimisation in the water cycle and operation of the infrastructures, but also transforms the workforce in the water sector. The third level is related to wider sociopolitical aspects of the urban water cycle. At this level, we consider two examples (Section 5): the gender issue and water governance more generally. In the discussion section, we explore pathways for the responsible use of $\mathrm{AI}$ and other digital technologies in the UWC, making the case for a 'hydrosocial' approach to A. We argue that this approach overcomes the artificial separations between nature, society, and technology, while integrating ethical and sociopolitical considerations from the outset.

\section{Theoretical and Methodological Underpinnings}

This investigation relied on a three-step method which involved the following: (1) desk research to review the theoretical literature (political ecology and hydrosocial science); (2) the development of criteria for the initial selection of applications and areas of impact; (3) interdisciplinary expert consultations-apart from the authors, consultations included renowned scholars from political science, environmental justice, philosophy, AI ethics, and environmental engineering - to validate the list and discuss the possible implications of digital water management.

The approach proposed in this paper takes its cue from urban political ecology (UPE) [20-23], a theoretical perspective that can be used to help unpack some of the main assumptions of the 'positive' or 'technocratic' approach to water digitalisation. UPE has traditionally explored the entanglements of power with the infrastructural provision in cities: instead of looking at infrastructure as a mere technological and apparently unproblematic issue, UPE scholars explore the political and conflictive dimension of technological and infrastructural projects [24]. Thus, the urban environment can be conceptualised as a socionatural hybrid. It embodies the relations, technological artefacts, networks, and flows that make urban life possible [25]. Building on the same metaphor of the hybrid, the concept of 'hydrosocial' aims to transcend nature-society binaries and envisions the circulation of water as a combined physical and social process [20,23]. Thus, water infrastructures and technologies of any kind-i.e., including the digital - need to be understood as an inseparable intertwining of cultural, political, and economic relations [25]. It follows that an evaluation of the impact of $\mathrm{AI}$ on the water sector needs to consider this hybrid nature and, importantly, place these applications in a wider sociopolitical context.

In this sense, urban political ecologists have begun to study the relationships between the deployment of water infrastructures, technologies, and governance within the shifting forms of capitalism and neoliberalism [21,26]. The growing importance of digital technologies in our society has brought about new forms of capital accumulation. Under so-called 
"cognitive capitalism", the industrial mode of production becomes obsolete and, at the same time, "the object of accumulation consists mainly of knowledge", which is now the primary source of value [27] (p. 57). A dysfunctional form of cognitive capitalism could be considered "surveillance capitalism", a term coined by Shoshana Zuboff, who refers to it as a "fully institutionalised new logic of accumulation" based on the prediction and modification of human behaviour [9]. A fundamental shift in this new regime is that day-to-day practices - therefore water-related ones are included-become a primary target of commercialisation strategies [10]. Importantly, and given the rapid pace at which this trend is advancing, our society is yet to find a way to govern Big Data: how will it be used, to what purpose, who decides, and who decides who decides are fundamental political questions that remain largely unanswered [9].

These questions are also profoundly relevant for how the 'digital revolution' in water will be understood and managed. Digital technologies such as AI, data-mining, and advanced monitoring have the potential to fundamentally transform the way we understand and collect data from water, as the sector becomes riddled with new ethical and political concerns. Bringing together UPE and hydrosocial approaches, the paper focuses on the choreographies of power, nature, and capitalism encapsulated in 'digital water' applications. The article asks: notwithstanding the benefits of these applications, to what extent are they obscuring instances of power and discrimination and what can be done to overcome these concerns?

\section{The Impact of AI on UWC: The Technical Level}

This section focuses on the technical level of 'digital water' issues and the associated concerns, as exemplified in two applications: sewer epidemiology and smart metering.

\subsection{Sewer Epidemiology}

Water has the potential to become one of society's key sources of information; according to Garrido-Baserba et al. [2], cities will soon be able to 'mine' their sewer systems for information in order to understand lifestyle habits and the overall health status of the population by measuring human biomarkers. Importantly, by collecting the data available in wastewater, public health decision making will be improved through rapid access to potential sources of epidemiological threat. According to 'optimist' accounts, in exchange for this information, users will be "continuously informed and guided about health (e.g., disease predisposition, recovering follow-ups, tailored health programs, etc.) and lifestyle (e.g., dietary recommendations, personal-suggested activities, sport-recommendation with its corresponding associated products, etc." [2].

However, if we look at this technology and its potentiality from a UPE perspective, several problems arise. As our current experiences with Big Data show us, the relationship between users and the firms which process and commercialise data is more like an extractive process than a fair exchange [9]. It is precisely this one-way process that makes Big Data possible, and it typically occurs in the absence of dialogue or consent. Similarly, in the case of data obtained via sewer mining, optimistic accounts of the benefits of advanced capacity for early detection of diseases do not consider the potential risks of this commodification of data.

Moreover, as the management of COVID-19 has shown, access to intimate data can be used as a tool of advanced surveillance. For instance, the ability to profile different neighbourhoods according to their lifestyle choices raises important threats to privacy, but furthermore, the access to this data can legitimate, even without the threat of health hazards, policies which reproduce inequalities and discrimination against the more vulnerable. For instance, it is known already that the pandemic disproportionately affected poor, black communities, not because of their 'irresponsible' habits, but because of their structural life conditions: dwelling in crowded houses increased the incidence of contagion. The selective lockdown of poor neighbourhoods is just an example of how biopolitics can be spun against these communities [28]. 
Allowing access to personal lifestyle data can have significant impacts on the lives of the citizens, since in some health systems-notoriously in the USA-lifestyle habits determine the degree of access to health services. A smoker pays up to 50\% more for health insurance, depending on the state [29]. Still, so far, the system relies on the 'honour' of the respondents and does not actually perform any checking; in other words, people can hide their habits, even if lying about them constitutes light fraud. A 'smart' system such as sewer epidemiology, which is able to detect eating habits, substance ingest, or other conducts which pose a threat to our health, could not only 'recommend' changes in diets, but also stigmatise and hinder medical autonomy.

Another important concern raised by sewer epidemiology is the potential publication of the databases and the eventual uses of this information. Even if the individual data are not made available - and therefore the European regulations on privacy are safeguardedthe publication of data even at a large geographical aggregation level can have an impact on certain communities. Wastewater can provide information about the level of intake of certain medical drugs in certain areas, which is in fact a valuable commercial information and can help target marketing campaigns for certain 'health' products. These instances require additional cautions that might be beyond the General Data Protection Regulation (GDPR) regulations, since they may be contrary to the principles declared in the recent AI Act of the European Commission from April 2021 (Article 5 of Title II) about the prohibition of any practice oriented to manipulate human behaviour [30].

\subsection{Smart Metering}

Smart meters installed in every household allow for continuous measuring of water consumption. Through this technique, more accessible data are available to both consumers and companies, and this can impact the way people relate to the service while opening countless possibilities for influencing consumption behaviour. From the utility point of view, it can allow for reductions in peak demands, improved demand forecasting, promotion of efficient appliances, and performance indicators. On the consumer side, smart meters are considered useful as they provide information on how and where water is used to allow the reduction of consumption or quick leak detection.

However, smart meters also present several concerns. The technology can be used to collect and commodify data on consumer behaviour, while the promised reduction in consumption is in part a result of disciplining consumers. Thus, Zetland [31] (p. 126) argues that " $[\mathrm{w}]$ ater meters transform water users from passive consumers [ ... ] into active customers entitled to value for money". A more responsible consumer is 'nudged' to consume less water by emphasising the opportunity to save money. The financial value of water is used to urge households to 'take control' over their bill while altering the ways in which they use water. Penetrating the intimacy of the home, smart meters assist in the transformation of the household into a revenue stream and, at the same time, serve to control behaviours and shape practices "associated with the political rule of finance" [32].

Critical literature has also shown that this continuous information about water consumption (combined with pricing mechanisms) may make citizens obsessed with reducing already low and essential water uses instead of focusing on other household expenses [33] (see also Section 5.1 on the gender dimension of this practice). Therefore, it could be argued that smart metering risks consolidating processes of commodification of the urban water supply, even for the most basic uses. At the same time, studies have shown that consumers from vulnerable groups are likely to need more help if they are to obtain the full benefits of smart metering [33].

Moreover, like the sewer epidemiology case, the publication of data can become a problem; even if individual data are strictly preserved and only aggregated data of water consumption at certain territorial levels are made available (at building level, at street level, at district level, etc.), these data can be crossed with other databases such as, for example, TV channel scheduling. This data crossing can yield information about which channel a certain territorial area is predominantly watching, with associated consequences 
for the advertising policies among others (for instance because there is a direct association between increasing use of water when advertisements happen on TV in the evenings). In Europe, the GRPD is trying to prevent these situations via the informed consent of users, but additional care is required when we are talking about aggregated data which can be analysed in forms that can also have an impact at the individual level [30].

\section{The Impact of AI on UWC: The Operational Level}

\subsection{Decision-Support Systems for Design and Operation of Water Treatment Plants}

Selecting the technology mix that can achieve the objectives assigned to urban water infrastructures is a complex task due to the proliferation of new technologies coupled with ever stricter water quality standards [34]. Environmental Decision Support Systems (EDSSs) are AI tools that have been helping operators and policymakers to tackle this problem. Created in the 1980s, the aim of these technologies was to provide decision-making support by combining mathematical models with qualitative knowledge. The use of ontologies and AI techniques specialising in the emulation of human behaviour have allowed EDSSs to be used as systems capable of integrating a wide diversity of knowledge and providing elements of discussion to reach consensual solutions.

While EDSSs have helped to improve decision making across the water cycle $[34,35]$, several pitfalls of this technology are worth reviewing. From an ethical perspective, the fact that they rely on the autonomous nature of AI systems raises issues of the potential loss of human control over decision making, which can yield ethically questionable outcomes. In the same line, the liability for harms resulting from the use of EDSSs remains ambiguous under many legal frameworks.

Application of a political ecology lens to this technique would highlight issues of power inequalities, especially due to how restrictive EDSSs are in terms of use. Thus, while the EDSS as a concept was very promising and there are numerous such systems already in place in the water management sector, the complexity of today's operations poses challenges to their implementation. The integration of expertise, models, statistical analysis, case-based systems, real-time, etc. is key to gaining useful decision-making knowledge. However, because of this diversity of inputs, EDSSs end up difficult to understand and employ for users others than large companies who can afford: (1) to employ data experts, process engineers, and software engineers who can connect different types of data sources, databases, etc.; or (2) software that can create easy-to-use, dynamic interfaces.

\subsection{Workforce}

The gradual uptake of AI technologies in the water sector will likely affect its workforce, like other economic sectors. From an optimistic perspective, AI has the potential to "free workers from repetitive tasks enabling them to focus on more highly skilled aspects" [2]. At the same time, digital water management will require a requalification of the workforce, including water researchers. According to the same authors, the implementation of effective Big Data exploitation will give birth to a "new generation of researchers/practitioners trained in engineering, statistics, and computer science through the creation of multidisciplinary training programs" [2]. Indeed, one of the objectives of the European strategy on AI is to prepare the society for the socioeconomic changes brought by AI, and in particular to provide support to businesses to strengthen the advanced digital skills of their workforce. Moreover, the Ethics Guidelines for Trustworthy AI of the High-Level Expert Group on AI introduce the education and training of AI stakeholders (including raising awareness of the potential impact of AI and their participatory role in shaping societal development) as a key method through which to ensure the responsible implementation of AI systems [36]. In this sense, the authors [2] are right to stress that the potential of AI comes from training more interdisciplinary researchers and professionals.

While the positive aspects of qualifying staff in managing these new technologies cannot be denied, there are more aspects to consider in this requalification than the purely technical ones. Firstly, the path of deskilling and reskilling involves a set of complexities 
which are rarely explored in the 'optimist' literature. Not all workers will be able to cope with the reskilling process-or will be willing to-and therefore they will inevitably be affected by redundancy. For most people, jobs are much more than just means to gain a living; they are intimately linked to personal identity, self-esteem, and social status, which will make this process particularly painful for a portion of existing water professionals. Depending on the pace at which AI replaces workers or makes them partially unfit for their positions, compensatory policies such as universal income should be explored [37], representing some form of "intergenerational solidarity between those disadvantaged today and those advantaged tomorrow, to ensure that the disruptive transition between the present and the future will be as fair as possible, for everyone" [13].

Secondly, there is also the danger of perpetuating the technocratic paradigm which already privileges technical skills. The water and AI specialists of tomorrow, with their versatile profiles, may represent an important step forward in understanding the inherent interdisciplinary character of the water sector itself. However, this is not achievable unless interdisciplinarity is understood in its entirety; issues such as values, ethics, and the social and political aspects of AI and of water management need to be part of the basic training of the new water professionals who will govern and manage the "digital water revolution".

\section{The Impact of AI on UWC: Sociopolitical Level}

In this section, we address the sociopolitical dimension of water digitalisation. We deal with the water governance aspects of water digitalisation and the gender implications.

\subsection{Water Governance}

The term 'governance' has gained increasing prominence in the scientific literature on water. As an analytical category, the governance perspective asks whether and how institutions can deal with the tasks assigned to them [38]. The governance approach has offered a more flexible (but also more elusive) way to conceptualise the political space, which includes the classic governmental processes-mainly laws, regulation, and policiesbut moves beyond it to include more scales, types of public and private actors, and the relationships between them [39].

In the water sector, AI can improve water governance especially by reducing uncertainty; AI capabilities can have a positive impact on policymaking and businesses by offering reliable predictions of climate conditions, water flows, and even envisaged behaviours of communities and actors, thus reducing risks [40]. However, the promise to offer certainty and reduce the complexities of decision making also has several downsides. A political ecology perspective would advise against the danger of excessively relying on $\mathrm{AI}$ algorithms for decision making in water governance, since it may consolidate the already reductionist and depoliticised water governance perspective that is dominant nowadays, according to which water is devoid of any cultural, symbolic, and political character. Consequently, its management is conscribed to the realm of technoscience and managerial means. Nevertheless, water is a paradigmatic "wicked problem" [40] imbued with social controversy and needs constant political renegotiations of potential solution paths [39]. Moreover, as Eric Swyngedouw reminds us, water is inherently political, and therefore subject to all manner of tensions, conflicts, and social struggles [22].

The depoliticisation of water is potentially negative because it privileges a dominant way to manage water over alternative ones. As shown in the political ecology literature, depoliticisation goes hand in hand with the commodification of water [41,42] which subordinates the use value of water (i.e., its qualitatively defined characteristics) to the exchange value (monetary price decided by the market). This commodification process implies that the only way to truly 'appreciate' a service is to pay for it (ideally at full market cost). Thus, in the AI-powered expert paradigm, if a value cannot be expressed in monetary terms, it risks not being included in decision making at all [43]. Consequently, service users are increasingly seen (and come to see themselves) as 'customers' instead of 'citizens', with 
public amenities perceived more like private commodities than public goods, concealing the complex social and labour arrangements behind their exchange price [43,44].

\subsection{Water, AI, and Gender}

Power imbalances and exploitation are key preoccupations of political ecologists; it is therefore no surprise that gender has been intensively studied, particularly in relation to water supply in developing countries [45-47]. Women are predominantly in charge of providing water for their families, often over very long distances, a fundamental task which does not enjoy social recognition. The responsibility of providing water intensifies the daily work of women and compromises their education and access to leisure, negatively impacting their health and quality of life [48]. These conditions may worsen in a climate change context, which access to water even more difficult [49].

Gender inequality in the water sector is not restricted to developing countries; globally, the water sector continues to employ far less women than men, especially in technical and managerial jobs. A World Bank study shows that women occupy less than a quarter of the total water professionals. Moreover, even if on average, 23 percent of engineers and managers in a utility are female, 32 percent of the sampled utilities had no female engineers and 12 percent had no female managers [50]. As AI penetrates more and more aspects of the water management sector, this will have an impact on how women will cope with digitalisation and will make them more likely to be affected by redundancy. Thus, as AI applications become an essential interface in the work environment, the pressure to reskill will be harder on women; this learning process usually takes place during 'leisure' time, when women carry heavier care burdens than. This is correlated with the gender dimension of the 'digital gap', meaning that girls and young women do not have equal access to technology and digital training, which negatively affects literacy and professional prospects [51].

Another area where the interplay between $\mathrm{AI}$, water, and gender is worth considering is in the decision making in urban water planning interventions. As noted in Section 4.2, AIbased systems using aggregated user data (or instance, about water use in the household through smart meters) are increasingly employed to envisage scenarios and legitimise policies in urban water projects $[40,52]$. If datasets are not disaggregated by sex and gender (as well as other identities), this means that policies regarding tariffs, water-saving schemes, or infrastructure programs will not factor in women's needs and opinions. This is especially important if we consider that care-related activities, which involve water use, are predominantly the responsibility of women. Using a gendered analysis, planners could gain a more accurate picture of communities, natural resource uses, households, and water users. Understanding the differences among and between women and men (who does what work, who makes which decisions, who uses water for what purpose, who controls which resources, who is responsible for different family obligations, etc.) can yield more effective results $[53,54]$. Moreover, the fact that only 22 percent of AI professionals are women certainly does not improve the chances that the interpretation of these data includes a gendered perspective [55].

It follows that woman should play a fundamental role in resource management and in the implementation of water technology and infrastructure projects. However, change is not at hand, with studies concluding that the interest of women in advancing within water governance is not well-supported by society, particularly in rural and peri-urban areas [46]. Governments and companies should strengthen women's participation and leadership, promote communication and education with a gender perspective, and ensure the collection of gender-disaggregated data.

\section{Discussion: A Hydrosocial Approach to Digital Water}

This paper aimed to move beyond the overly optimistic approaches to 'digital water' management and paint a more nuanced picture of this crucial transformation of the sector. Using a hydrosocial and Urban Political Ecology theoretical lens (see also [56]), the analysis 
highlighted that the gradual penetration of Big Data and AI-related technologies in the water sector can yield opportunities but also have negative effects such as increased surveillance, lack of accountability, workforce exclusion, discrimination, injustice, and loss of democratic quality. These are also areas where more data and research is needed.

How to tackle these concerns? The available ethical frameworks provide some valuable guidance. Thus, the High-Level Expert Group on AI have defined a set of requirements that AI practitioners need to put in place to guarantee a Trustworthy AI: human agency and oversight; technical robustness and safety; privacy and data governance; transparency; diversity, non-discrimination, and fairness; societal and environmental wellbeing; and accountability [36]. However, these principles require further operationalisation for specific AI-based systems in the water domain.

From the overview of opportunities and concerns presented in this paper emerges that a hydrosocial approach to digital water is timely and necessary. It envisions AI as a force in the service of the human right to water, the implementation of which needs to be (1) critical, in that it takes into consideration gender, race, class, and other sources of discrimination and orients algorithms according to key principles and values; (2) democratic and participatory, i.e., it combines a concern for efficiency with sensitiveness to issues of fairness or justice and a shift towards mechanisms that ensure democratic control over the applications, while overcoming the split between experts and society; and (3) interdisciplinary, meaning that it integrates social sciences and 'technical' / natural sciences from the outset, in all applications.

Applying these principles to the risks identified here, the following recommendations emerge:

(1) Risk of surveillance: applications such as sewer epidemiology and smart metering have the capacity to obtain intimate private information which, if not properly protected, can become a tool of increased surveillance and oppression [57]. To this purpose, the direct and indirect uses of data coming from water must be limited, particularly when talking about aggregated data combined with nonwater information. In the EU, the TrustworthyAI ethical guidelines' [36] recommendations and AI Act provide a proper context to guarantee privacy, autonomy, and nondiscrimination; however, they only apply in the EU and they need further operationalisation for the water domain.

(2) Risk of biased decision making: the advance of environmental decision-support systems, agent-based modelling, and Big-Data-powered scenarios for policymaking can be nonrepresentative, biased, and lack accountability. Therefore, there needs to be an increased preoccupation with standards of transparency and access to knowledge. Standards should be complemented by training programmes and integration of a wider variety of disciplines, knowledges, and perspectives in the design of the models, lowering the expertise and gender barrier.

(3) Risk of workforce exclusion: digitalisation will inevitably impact the water workforce, provoking redundancy and the need for reskilling. To avoid the worst consequences for economic means, wellbeing, or dignity of this workforce, there needs to be increased awareness on the part of the policymakers and corporations; the advance of AI should be approached systemically, in an integrated way, and complemented with investments in training, while exploring substantial solidarity programmes such as a universal income. Specific attention needs to be paid to training for women in future professional roles, starting from acknowledgment of the gender dimension of the digital divide.

(4) Risk of democratic quality loss: water digitalisation is largely driven by the private sector, which welcomes the opportunity of reducing risks and complexity of decisionmaking. However, this transformation should not lead to further commodification of water and the exclusion of communities from decisions in favour of gaining efficiency. Therefore, the digitalisation of the water sector should go hand in hand not only with public control, but also with enhancing mechanisms of direct, democratic participation 
in the water governance. Moreover, when we talk about the deployment of new technologies in developing countries, it is especially important to consider the cultural dimension and indigenous knowledges, and to understand how it will affect social relations and what socioeconomic changes need to be foreseen to adopt, adapt to, or reject the water digitalisation processes. It is also necessary to consider possible trade-offs raised from the compliance of all these ethical requirements, where technical concepts such as efficiency or performance might be confronted with sociopolitical requirements. Consequently, responsible $\mathrm{AI}$ is as much a question of trustworthy $\mathrm{AI}$ techniques as one of accountable governance.

(5) Risk of injustice and gender discrimination: water, gender, and AI are inextricably linked, as the digitalisation of water will likely enhance existing power imbalances in the sector and the lack of representation of women and other gendered identities in water-related interventions. To counteract the bias incorporated in AI applications see also [58], gender should be mainstreamed in planning, implementation, and evaluation of programs. Methodologies such as gender analysis, social mapping, and sexand gender-disaggregated data should be further encouraged. Promoting an active participation of different gendered people throughout the design, implementation, and evaluation stages can help to ensure that their needs are represented. Additionally, more research correlating data on gender, AI, and water technologies is needed to improve knowledge and awareness on this topic.

\section{Conclusions}

This paper provides an informed reflection about the ethical and political concerns associated with the deployment of digital technologies in the water sector, with a focus on the Urban Water Cycle. Using the theoretical lens of urban political ecology, and the literature on hydrosocial cycles, we analysed relevant examples of how digitalisation impacts the technical, operational, and sociopolitical levels of the urban water cycle, respectively. The applications were selected using expert consultations. The article did not aim to offer an exhaustive review of the 'digital water' issue, but rather to illustrate how we canand should-be thinking about this issue. Our results show that while digitalisation can have a positive impact on the urban water cycle, it can also generate concerns in terms of personal and collective rights. In the discussion, we provide paths for further research that approach water digitalisation in a critical, theory-guided and interdisciplinary way. Indeed, interdisciplinarity is key to a safe and fair digital transition, and this article takes this conviction onboard by relying on complementary views of scholars from political science, water engineering, and AI. This first attempt to bring together a diversity of voices can serve as a basis for a timely debate in the water sector that would help to prevent the establishment of dysfunctional ways of functioning, which may be extremely challenging to reverse.

Author Contributions: Conceptualisation, L.A.P. and M.P.; methodology, À.C., M.G.-B., M.V. and K.G.; formal analysis, À.C., L.A.P. and K.G.; writing-original draft preparation, L.A.P., M.P. and M.V.; writing—review and editing À.C., M.G.-B. and K.G.; supervision, M.P. and K.G. All authors have read and agreed to the published version of the manuscript.

Funding: This research received no external funding.

Institutional Review Board Statement: Not applicable.

Informed Consent Statement: Not applicable.

Data Availability Statement: Not applicable.

Conflicts of Interest: The authors declare no conflict of interest. 


\section{References}

1. Oral, H.V.; Carvalho, P.; Gajewska, M.; Ursino, N.; Masi, F.; van Hullebusch, E.D.; Kazak, J.K.; Exposito, A.; Cipolletta, G.; Andersen, T.R.; et al. A review of nature-based solutions for urban water management in European circular cities: A critical assessment based on case studies and literature. Blue-Green Syst. 2020, 2, 112-136. [CrossRef]

2. Garrido-Baserba, M.; Corominas, L.; Cortés, U.; Rosso, D.; Poch, M. The Fourth Revolution in the Water Sector Encounters the Digital Revolution. Environ. Sci. Technol. 2020, 54, 4698-4705. [CrossRef] [PubMed]

3. International Water Association. Digital Water. Industrial Leaders Chart the Transformation Journey. Available online: https: / /iwa-network.org/publications / digital-water/ (accessed on 12 February 2022).

4. Sun, A.Y.; Scanlon, B.R. How can Big Data and machine learning benefit environment and water management: A survey of methods, applications, and future directions. Environ. Res. Lett. 2019, 14, 073001. [CrossRef]

5. Corominas, L.; Garrido-Baserba, M.; Villez, K.; Olsson, G.; Corteś, U.; Poch, M. Transforming Data into Knowledge for Improved Wastewater Treatment Operation: A Critical Review of Techniques. Environ. Model. Softw. 2018, 106, 89-103. [CrossRef]

6. Knüsel, B.; Zumwald, M.; Baumberger, C.; Hadorn, G.H.; Fischer, E.M.; Bresch, D.N.; Knutti, R. Applying big data beyond small problems in climate research. Nat. Clim. Chang. 2019, 9, 196-202. [CrossRef]

7. Poch, M.; Garrido-Baserba, M.; Corominas, L.; Perelló-Moragues, A.; Monclús, H.; Cermerón-Romero, M.; Melitas, N.; Jiang, S.; Rosso, D. When the fourth water and digital revolution encountered COVID-19. Sci. Total Environ. 2020, 744, 140980. [CrossRef]

8. Doorn, N. Artificial intelligence in the water domain: Opportunities for responsible use. Sci. Total Environ. 2020, 755, 142561. [CrossRef]

9. Zuboff, S. Big other: Surveillance Capitalism and the Prospects of an Information Civilization. J. Inf. Technol. 2015, 30, 75-89. [CrossRef]

10. Zuboff, S. The Age of Surveillance Capitalism; Profile Books: London, UK, 2019.

11. Harari, Y.N. Reboot for the AI revolution. Nature 2017, 550, 324-327. [CrossRef]

12. Han, B.-C. Non things. Upheaval in the Lifeworld; Polity Press: Cambridge, UK, 2020.

13. Floridi, L. The Onlife Manifesto. Being Human in a Hyperconnected Era; Springer Open: Berlin/Heidelberg, Germany, $2015 ;$ p. 264.

14. Jobin, A.; Ienca, M.; Vayena, E. The global landscape of AI ethics guidelines. Nat. Mach. Intell. 2019, 1, 389-399. [CrossRef]

15. Ryan, M.; Stahl, B. Artificial intelligence ethics guidelines for developers and users: Clarifying their content and normative implications. J. Inf. 2015, 29, 62-84. [CrossRef]

16. Gupta, A. AI in Smart Cities: Privacy, Trust, and Ethics. New Cities. Available online: https://newcities.org/the-big-picture-aismart-cities-privacy-trust-ethics / (accessed on 12 February 2022).

17. Hagendorf, T. The Ethics of AI Ethics: An Evaluation of Guidelines. Minds Mach. 2015, 30, 99-120. [CrossRef]

18. Poch, M.; Comas, J.; Rodrıguez-Roda, I.; Sanchez-Marrèb, M.C. Designing and building real environmental decision support systems. Environ. Model. Softw. 2003, 19, 857-873. [CrossRef]

19. Funtowicz, S.O.; Ravetz, J.R. Science for the post-normal age. Futures 1993, 25, 739-755. [CrossRef]

20. Boelens, R.; Hoogesteger, J.; Swyngedouw, E.; Vos, J.; Wester, P. Hydrosocial territories: A political ecology perspective. Water Int. 2016, 41, 1-14. [CrossRef]

21. Loftus, A. Everyday Environmentalism: Creating an Urban Political Ecology; University of Minnesota Press: Minneapolis, MN, USA; London, UK, 2015.

22. Swyngedouw, E. Dispossessing H2O: The contested terrain of water privatization. Capital. Nat. Social. 2005, 16, 81-98. [CrossRef]

23. Swyngedouw, E. Liquid Power: Contested Hydro-Modernities in 20th Century Spain; MIT Press: Cambridge, MA, USA, 2015.

24. Heynen, N.; Kaika, M.; Swyngedouw, E. In the Nature of Cities: Urban Political Ecology and the Politics of Urban Metabolism; Routledge: London, UK; New York, NY, USA, 2006.

25. Gandy, M. Concrete and Clay: Reworking Nature in New York City; MIT Press: Cambridge, MA, USA, 2002.

26. Allen, J.; Pryke, M. Financialising household water: Thames Water, MEIF, and 'ring-fenced' politics. Camb. J. Reg. Econ. Soc. 2013, 6, 419-439. [CrossRef]

27. Moulier-Boutang, Y. Cognitive Capitalism; Polity Press: Cambridge, UK, 2012.

28. Durizzo, K.; Asiedu, E.; Van der Merwe, A.; Van Niekerk, A.; Günther, I. Managing the COVID-19 pandemic in poor urban neighbourhoods: The case of Accra and Johannesburg. World Dev. 2021, 137, 105175. [CrossRef]

29. Health Markets. What You Need to Know About Smoking and Health Insurance. Available online: https://www.healthmarkets. com/content/smoking-and-health-insurance (accessed on 1 October 2021).

30. European Commission. Laying down Harmonised Rules on Artificial Intelligence (Artificial Intelligence Act) and Amending Certain Union Legislative Acts. 2021. Available online: https:/ / eur-lex.europa.eu/legal-content/EN/TXT/HTML/?uri=CELEX: 52021PC0206\&from $=\mathrm{EN}$ (accessed on 30 January 2022).

31. Zetland, D. The struggle for residential water metering in England and Wales. Water Altern. 2016, 9, 120-138.

32. Loftus, A.; March, H.; Nash, F. Water Infrastructure and the Making of Financial Subjects in the South East of England. Water Altern. 2016, 9, 319-335.

33. March, H.; Morote, A.-F.; Rico, A.-M.; Saurí, D. Household smart metering in Spain: Experiences from remote meter reading in Alicante. Sustainability 2017, 9, 582. [CrossRef]

34. Hadjimichael, A.; Comas, J.; Corominas, L. Do machine learning methods used in data mining enhance the potential of decision support systems? A review for the urban water sector. AI Commun. 2016, 29, 747-756. [CrossRef] 
35. Garrido-Baserba, M.; Reif, R.; Hernández, F.; Poch, M. Implementation of a knowledge-based methodology in a decision support system for the design of suitable wastewater treatment process flow diagrams. J. Environ. Manag. 2012, 112, 384-391. [CrossRef] [PubMed]

36. High-Level Expert Group on Artificial Intelligence, Ethics Guidelines for Trustworhy AI. Available online: https://www.aepd.es/ sites/default/files/2019-12/ai-ethics-guidelines.pdf (accessed on 3 November 2021).

37. Cowls, J.; Floridi, L.; Mariarosaria, T. The Challenges and Opportunities of Ethical AI. Available online: https:/ / digitransglasgow. github.io/ArtificiallyIntelligent/contributions/04_Alan_Turing_Institute.html (accessed on 22 October 2021).

38. Takeda, T.; Kato, J.; Matsumura, T.; Murakami, T.; Abeynayaka, A. Governance of Artificial Intelligence in Water and Wastewater Management: The Case Study of Japan. Hydrology 2021, 8, 120. [CrossRef]

39. Meisch, S. I Want to Tell You a Story: How Narrative Water Ethics Contributes to Re-theorizing Water Politics. Water 2019, 11, 631. [CrossRef]

40. Perello-Moragues, A.; Poch, M.; Sauri, D.; Popartan, L.A.; Noriega, P. Modelling domestic water use in metropolitan area using socio-cognitive agents. Water 2020, 13, 1024. [CrossRef]

41. Bakker, K. From State to Market?: Water Mercantilización in Spain. Environ. Plan. A 2002, 34, 767-790. [CrossRef]

42. Bakker, K. Water: Political, biopolitical, material. Soc. Stud. Sci. 2012, 42, 616-623. [CrossRef]

43. McDonald, D.A. To corporatize or not to corporatize (and if so, how?). Util. Policy 2016, 40, 107-114. [CrossRef]

44. Clarke, J.; Newman, J.; Smith, N.; Vidler, E.; Westmarland, L. Creating Citizenconsumers: Changing Publics and Changing Public Services; Sage Press: Thousand Oaks, CA, USA, 2007.

45. Andajani, S.; Chirawatkul, S.; Saito, E. Gender and Water in Northeast Thailand: Inequalities and Women's Realities. J. Int. Women's Stud. 2015, 16, 200-212.

46. de San, J.A.S.R. Gender and water governance in Mexico. Manag. Environ. Qual. Int. J. 2019, 30, 695-713.

47. Silva, B.B.; Sales, B.; Lanza, A.C.; Heller, L.; Rezende, S. Water and sanitation are not gender-neutral: Human rights in rural Brazilian communities. Water Policy 2020, 22, 102-120. [CrossRef]

48. Varua, M.E.; Ward, J.; Maheshwari, B.; Dave, S.; Kookana, R. Groundwater management. Water 2018, 11, 1959.

49. Eastin, J. Climate change and gender equality in developing states. World Dev. 2018, 107, 289-305. [CrossRef]

50. World Bank. Women in Water Utilities. Breaking Barriers. 2019. Available online: https://openknowledge.worldbank.org/ bitstream/handle/10986/32319/140993.pdf (accessed on 1 January 2022).

51. UNICEF. What We Know about the Gender Digital Divide for Girls: A Literature Review. 2021. Available online: https: //www.unicef.org/eap/media/8311/file (accessed on 22 January 2022).

52. Smith, G.; Rustagi, I. When Good Algorithms Go Sexist: Why and How to Advance AI Gender Equity, Standford Social Innovation Review. 2021. Available online: https://ssir.org/articles/entry/when_good_algorithms_go_sexist_why_and_how_to_advance_ ai_gender_equity\# (accessed on 12 February 2022).

53. UNDP. Resource Guide for Mainstreaming Gender in Water Management. Available online: https://www.undp.org/ publications / resource-guide-mainstreaming-gender-water-management (accessed on 12 August 2021).

54. Beebeejaun, Y. Gender, urban space, and the right to everyday life. J. Urban Aff. 2016, 39, 323-334. [CrossRef]

55. Young, E.; Wajcman, J.; Sprejer, L. Where are the Women? Mapping the Gender Job Gap in AI. Policy Briefing: Full Report. The Alan Turing Institute. 2021. Available online: https://www.turing.ac.uk/news/where-are-women-mapping-gender-job-gap-ai (accessed on 30 January 2022).

56. Kostakis, V.; Roos, A.; Bauwens, M. Towards a political ecology of the digital economy: Socio-environmental implications of two competing value models. Environ. Innov. Soc. Transitions 2016, 18, 82-100. [CrossRef]

57. Noble, S.U. Algorithms of Oppression; New York University Press: New York, NY, USA, 2018. [CrossRef]

58. Ferrer, X.; van Nuenen, T.; Such, J.M.; Cote, M.; Criado, N. Bias and Discrimination in AI: A Cross-Disciplinary Perspective. IEEE Technol. Soc. Mag. 2021, 40, 72-80. [CrossRef] 